\title{
EL TELETRABAJO \\ EN LAS ADMINISTRACIONES PÚBLICAS
}

\author{
Telework in Public Administrations
}

\author{
Alicia Villalba Sánchez \\ Prof. ${ }^{\text {a }}$ contratada interina de Derecho del Trabajo y de la Seguridad Social \\ Departamento de Derecho Especial y de la Empresa \\ Universidad de Santiago de Compostela
}

Orcid: 0000-0001-8188-4810

DOI: 10.1387/lan-harremanak. 17933
Recibido el 29 de abril de 2017

Aceptado el 11 de mayo de 2017

\section{ABSTRACT}

La aplicación de las nuevas tecnologías de la información y de la comunicación en el trabajo ha supuesto una transformación de la prestación de servicios. Lejos de constituir un mero instrumento tendente a facilitar su ejecución, las posibilidades que ofrece una tecnología en continua evolución han difuminado el vinculo de subordinación que media entre el empleador y el prestador de servicios en aquellos puestos de trabajo cuyo desempeño exige una mayor cualificación y especialización del trabajador. Siendo las Administraciones Públicas organizaciones donde abundan dichos puestos de trabajo, se comprende la relevancia que en las mismas adquiere la implantación del teletrabajo. El presente estudio aborda su recepción en la Administración General del Estado así como en las Administraciones autonómicas, haciendo hincapié en las virtudes y carencias que presenta su régimen jurídico.

Palabras clave: Administraciones Públicas, nuevas tecnologías de la información y de la comunicación, teletrabajo. 
The implementation of new information and communication technologies in the workplace has led to a transformation of the work culture. The opportunities offered by a constantly evolving technology have blurred the subordination between the employer and the employee, mainly when the latter is highly qualified. Given Public Administrations are rich in this kind of staff, telework could play a relevant role. This paper deals with telework deployment into the Spanish Public Administrations, with particular emphasis on the advantages and deficiencies of its framework.

Keywords: Public Administrations, new information and communication technologies, telework. 


\section{SUMARIO}

Sumario: 1. Introducción. 2. El teletrabajo en las Administraciones Públicas. 2.1. El teletrabajo en la Administración General del Estado. 2.2. El teletrabajo en la Administración de las Comunidades Autónomas. 2.2.1. Marco normativo y concepto. 2.2.2. Ámbito de aplicación. 2.2.3. Procedimiento de selección. 2.2.4. Contenido de la prestación. 3. Conclusión. 4. Bibliografía.

\section{Introducción}

La aplicación en el trabajo de las tecnologías de la información y de la comunicación no constituye novedad alguna. No ha sido preciso aguardar hasta las últimas décadas del siglo xx para constatar la utilidad que puede proporcionar el uso en el entorno laboral de instrumentos como el teléfono. No obstante, el desarrollo tecnológico alcanzado a partir de ese momento ha cobrado tal relevancia que lo que otrora no era sino un mero instrumento que mejoraba la prestación de servicios ha dado pábulo a una transformación radical de la forma de trabajar.

En el seno de esta revolución tecnológica han surgido unos puestos de trabajo cada vez más especializados que, a su vez, demandan trabajadores dotados de una elevada formación. El desarrollo alcanzado y la cualificación del personal han hecho posible una prestación de servicios cada vez más autónoma. Tal es así que, a día de hoy, las notas características de la prestación objeto del Derecho del Trabajo parecen desvanecerse. Merece ser reinterpretada la subordinación (Pérez de los Cobos, 2005: 1315), pues el trabajador que emerge en este nueva era tecnológica goza de una independencia que impide su sujeción a órdenes y directrices constantes en cuanto atañe a la ejecución de su prestación, máxime cuando la misma requiere la posesión de unos conocimientos específicos de los cuales carece su superior jerárquico. Correlato de lo afirmado es la adaptación de las facultades empresariales de control, que se centrarán en la constatación del resultado alcanzado por el trabajador (Thibault, 2000: 46). Cobra así importancia la determinación de los objetivos cuya consecución se pretende, y la responsabilidad del trabajador en el correcto cumplimiento de la prestación debida.

La ausencia de una dirección y control continuos de la actividad del trabajador ha permitido el desempeño de sus funciones fuera de las dependencias de la empresa, lo cual significa que también se difumina la ajenidad, nota caracterís- 
tica de la prestación que, entre sus diversas manifestaciones, exige que el trabajo se desempeñe en los locales del empresario, y con instrumentos por él proporcionados. De ahí el resurgimiento del trabajo a distancia, antaño destinado a la ejecución de prestaciones que requería escasa cualificación (Ferreiro, 2015: 47).

Consciente de su renovada importancia, el legislador de 2012 acometió la regulación del trabajo a distancia en el art. 13 del ahora Real Decreto Legislativo $2 / 2015$, de 23 de octubre, por el que se aprueba el texto refundido de la Ley del Estatuto de los Trabajadores ${ }^{1}$ —en adelante, ET- Dicho artículo lo define como aquél en el que la prestación se realice "de manera preponderante en el domicilio del trabajador o en el lugar libremente elegido por éste», incluyendo en la definición de trabajo a distancia una de sus modalidades, a saber: el trabajo a domicilio. Cambia así el tenor del precepto anteriormente vigente, que aludía al "trabajo a domicilio», en pos de la construcción de un concepto genérico donde encuentra cabida aquél, pero también cualquier otra forma de trabajo no presencial (Sempere y Kahale, 2013: 9). Es de advertir que en ningún momento se alude a la utilización de las nuevas tecnologías de la información y de la comunicación en el desempeño del trabajo a distancia, rasgo característico de una especie perteneciente a aquel género: el teletrabajo. Curiosamente, se refiere a ella en la Exposición de Motivos de la Ley 3/2012, de 6 de julio, de medidas urgentes para la reforma del mercado laboral ${ }^{2}$, razón por la cual la doctrina ha considerado que "el legislador ha querido introducir el teletrabajo a través de la nueva figura del contrato de trabajo a distancia» (Purcalla y Preciado, 2013: 215).

Sí lo hizo en su momento el Acuerdo marco Europeo sobre Teletrabajo, firmado el 16 de julio de 2002 en Bruselas, a iniciativa de la Comisión Europea, por los interlocutores sociales más relevantes de ámbito europeo, cuyo apartado 2 entiende por tal "una forma de organización y/o de realización del trabajo» caracterizada por el uso de las tecnologías de la información, donde una prestación, que se podría desempeñar en los locales de a empresa, se efectúa fuera de éstos de forma regular.

Es esta especie de trabajo a distancia la que centra la atención del presente trabajo, habida cuenta del reto que supone regular de manera adecuada una nueva forma de prestar servicios donde la inmediatez geográfica y el vínculo de subordinación se debilitan notablemente. Además del interés jurídico que presenta, el teletrabajo merece ser abordado en atención a los objetivos susceptibles de ser alcanzados con su correcta regulación y aplicación. Amén de los que repercuten en una mejor organización de los recursos humanos de la empresa, con el consecuente ahorro de costes e incremento de la eficiencia que ello comporta, destaca la consecución de un mayor bienestar del trabajador que gana autono-

\footnotetext{
1 BOE n. ${ }^{\circ} 255$, de 24 octubre 2015.

2 BOE n.o 162, de 7 julio 2012.
} 
mía a la hora de compatibilizar su prestación de servicios con sus circunstancias personales. Dejando a un lado las ventajas que su aplicación surte en la relación individual de trabajo, existen también intereses sociales a cuya satisfacción contribuiría en gran medida su adecuada implementación. Se alude, por ejemplo, a la reducción de las emisiones dańinas para la atmósfera que supone la disminución de los desplazamientos innecesarios de trabajadores, o al reparto más equilibrado de la población que se podría conseguir permitiendo un desempeño de la prestación de servicios menos centralizado en torno a las grandes urbes.

Por todo ello procede abordar el régimen jurídico aplicable al teletrabajo, mas la amplitud del objeto de estudio exige una mayor concreción del tema a tratar. Toda vez que el teletrabajo constituye una modalidad de prestación de servicios idónea para el desempeño de aquellos puestos de trabajo que exigen una mayor cualificación - aunque éstos no agoten su ámbito de aplicación, existiendo cierta "teletaylorización» que afecta a puesto de teletrabajo donde la prestación es más rutinaria (Belzunegui, 2008: 137)_, y éstos abundan en las Administraciones Públicas se considera pertinente analizar el marco normativo aplicable al teletrabajo en aquéllas. Huelga ańadir el compromiso que éstas tienen, en calidad de empleador, para con el bienestar de sus propios trabajadores, la eficiencia en la gestión pública y la salvaguardia del medio ambiente.

Pese a ello, es sabido que el legislador no siempre se adapta de manera suficientemente rápida a la realidad social que ha de regular. Muestra de ello es la ausencia de mención alguna al teletrabajo en el Real Decreto Legislativo 5/2015, de 30 de octubre, por el que se aprueba el texto refundido de la Ley del Estatuto Básico del Empleado Público ${ }^{3}$ —en adelante, EBEP_- Ante esta laguna, es menester abordar el marco normativo específico diseñado para el teletrabajo en la Administración General del Estado, así como en las Administraciones de las Comunidades Autónomas, algunas de las cuales han desarrollado iniciativas dignas de mención.

\section{El teletrabajo en las Administraciones Públicas}

\subsection{El teletrabajo en la Administración General del Estado}

En cuanto concierne a la Administración General del Estado, procede hacer alusión al Acuerdo del Consejo de Ministros de 4 de marzo de 2005, por el que se aprobó el Plan Concilia que, entre otros compromisos, previó una serie de medidas para hacer efectiva la conciliación de las responsabilidades profesionales con la vida personal y familiar en el ámbito del empleo público.

${ }^{3}$ BOE n. ${ }^{\circ} 261$, de 31 octubre 2015. 
En el marco de aquél fue puesto en práctica un Plan piloto para la aplicación de técnicas de teletrabajo para los empleados públicos por el Ministerio de Administraciones Públicas, orientado al favorecimiento de la conciliación de la vida laboral, familiar y personal (Belzunegui, 2008: 144). Una vez concluida esta experiencia piloto, los resultados alcanzados fueron traídos a colación para hacer extensiva la posibilidad de realizar este tipo de experiencias a otros Departamentos, mediante la Orden APU/1981/2006, de 21 de junio, por la que se promueve la implantación de programas piloto de teletrabajo en los departamentos ministeriales ${ }^{4}$.

En ella se alude al teletrabajo, ora como una «nueva fórmula basada en las tecnologías de la información" que posibilita el desarrollo total o parcial de la jornada laboral desde un lugar distinto al de su centro de trabajo, ora como una "nueva forma de organización de la prestación laboral». Ya en su texto articulado, se define como una "modalidad de prestación de servicios de carácter no presenciali, en virtud de la cual un empleado de la Administración General del Estado puede desarrollar parte de su jornada laboral mediante el uso de medios telemáticos desde su propio domicilio. Se configura así como una prestación de trabajo a desarrollar en alternancia con la presencial, previendo así el indeseable aislamiento en que puede recaer el trabajador. Si bien el anterior matiz merece una favorable acogida, no sucede lo mismo con la alusión al domicilio del trabajador como lugar a desarrollar los servicios no presenciales, ya que circunscribe el teletrabajo a una de sus modalidades: el teletrabajo a domicilio (Sierra, 2011: 130).

Esta Orden se dictó con el propósito de posibilitar la puesta en marcha de programas piloto de teletrabajo en los departamentos ministeriales y sus organismos públicos vinculados o dependientes, garantizando, en todo caso, la voluntariedad de los empleados públicos que decidan participar. Al margen de esta precisión, que trae a colación la singular relevancia del consentimiento del trabajador (Thibault, 2006: 382), la Orden se limita a desgranar los extremos a contemplar por las experiencias piloto que hubieran de ponerse en práctica.

En ella se precisa la necesidad de incluir en cada programa los puestos de trabajo afectados, atendiendo a la naturaleza de sus funciones que, evidentemente, han de permitir su ejecución de manera no presencial. Se excluyen, por consiguiente, todos aquéllos que requieran la presencia del trabajador. Con arreglo a este criterio, queda abierta la posibilitad de limitar la opción de teletrabajar en supuestos en los cuales la presencia del trabajador sea conveniente, pero no inexcusable. Se antoja éste un matiz digno de crítica, máxime cuando el teletrabajo de que se trata se desarrolla, como se ha puntualizado, de manera parcial o en alternancia con la prestación de trabajo presencial.

${ }^{4}$ BOE n. ${ }^{\circ}$ 149, de 23 junio 2006. 
Según la citada Orden, esta modalidad estará a disposición de los empleados en servicio activo que reúnan los conocimientos en ofimática suficientes, siempre y cuando lo soliciten. Cada plan ha de determinar el número máximo de participantes así como su procedimiento de selección, la duración del propio programa y la de la prestación de servicios no presenciales en función de cada tipo de jornada. Se impone determinar también en cada plan el órgano encargado del control y los criterios para llevarlo a cabo, así como el sistema de evaluación del trabajo desarrollado de forma no presencial.

Nótese que la propia Orden destaca, entre sus ventajas, la identificación de los objetivos y la evaluación del grado de su cumplimiento, especialmente desde el punto de vista del empleador. A tal efecto, se consideraría preferible aludir al rendimiento del trabajador (Gárate, 1984: 34), toda vez que un objetivo puede o no alcanzarse exclusivamente a través del esfuerzo del trabajador. De esta guisa, no cabría sancionar al trabajador por la no consecución de un objetivo de imposible cumplimiento. Desde la perspectiva del empleado, hace hincapié en el incremento de su posibilidad de conciliar su vida personal con el desarrollo profesional. Lejos de tratarse de intereses contrapuestos, una adecuada determinación del sistema llamado a evaluar el rendimiento del trabajador se erige en la mejor garantía de un teletrabajo que permita la adecuada conciliación de la vida laboral, personal y familiar. Nótese que, además, al personal que participe en dichos programas no le será de aplicación de los criterios generales sobre jornada y horarios, extremo que requiere una determinación razonable del rendimiento a alcanzar.

Del marco normativo expuesto, sorprende la ausencia de alusión alguna a la salvaguardia de intereses existentes al margen de la conciliación de la vida personal, familiar y laboral, como la preservación del medio ambiente o la redistribución de la población hacia el ámbito rural. También el relegado papel que se atribuye a las organizaciones sindicales (art. 2).

Procede también hacer alusión a la publicación del Manual para la implantación de programas piloto de teletrabajo en la Administración General del Estado por el Ministerio de Administraciones Públicas. Aunque se trate de un documento informativo, carente de eficacia jurídica, sirve para confirmar la conciliación de la vida personal, familiar y laboral como objetivo primordial de la normativa estatal, al que se añaden la potenciación del trabajo en términos objetivos, al margen del tiempo de presencia, el aumento del compromiso y motivación del personal y la disminución del absentismo laboral. Por lo demás, su contenido se limita a concretar aspectos del programa piloto como el número de trabajadores que pueden participar, el procedimiento de selección, su duración, su alternancia con el trabajo presencial, la definición de los puestos susceptibles de ser desempeńados a través de esta modalidad y demás aspectos vinculados a la formación y a la prevención de riesgos laborales. 
Habida cuenta del carácter experimental de estos programas, la Orden dispone que concluidos éstos, incumbe a los departamentos y organismos informar al Ministerio de Administraciones Públicas, a fin de efectuar un análisis global integrado sobre su implantación. Transcurrido este período de experimentación, el gobierno elaboró un Proyecto de Real Decreto por el que se regula el Teletrabajo en la Administración General del Estado, pero sin someterlo a las fases previas de consulta y negociación con las organizaciones sindicales, carencia puesta de relieve por el dictamen del Consejo Económico y Social ${ }^{5}$ (Sierra, 2011: 130). Dicha carencia fue subsanada en el Proyecto de Real Decreto por el que se regula el Teletrabajo, el 8 de mayo de 2007, cuyo aciago destino recomienda dejar a un lado su estudio para pasar a abordar la normativa autonómica en la materia, dado que a día de hoy es la única en vigor que ofrece una regulación sistemática del teletrabajo en las Administraciones Públicas.

\subsection{El teletrabajo en la Administración de las Comunidades Autónomas}

\subsubsection{Marco normativo y concepto}

En el ámbito autonómico, procede hacer referencia al Decreto n. 9 9/2011, de 17 de marzo, por el que se regula la jornada de trabajo no presencial mediante teletrabajo en la Administración de la Comunidad de Castilla y León ${ }^{6}$ —en adelante, Decreto castellanoleonés_; al Decreto n. ${ }^{\circ}$ 92/2012, de 29 de mayo, por el que se aprueba el Acuerdo sobre la prestación del servicio en la modalidad no presencial mediante la fórmula del teletrabajo por el personal empleado público de la Administración General de la Comunidad Autónoma de Euskadi y sus Organismos Autónomos ${ }^{7}$ —en adelante, Decreto vasco—; al Decreto n. ${ }^{\circ} 127 / 2012$, de 6 de julio, por el que se regula la prestación del servicio en la modalidad no presencial, mediante la fórmula del teletrabajo, en la Administración de la Comunidad Autónoma de Extremadura ${ }^{8}$ —en adelante, Decreto extremeño-, que prevé una implantación progresiva del mismo a través de programas experimentales; al Decreto n. ${ }^{\circ} 36 / 2013$, de 28 de junio, por el que se regula la modalidad de prestación de servicios mediante teletrabajo en la Administración de la Comunidad Autónoma de las Illes Balears 9

5 Consultado el día 29 abril 2017 en el siguiente enlace: http://www.csit.es/hospedasw/arbol_ csit/admon_estado/modificacionleyes/23.04dictamenteletrabajo.pdf.

6 BO. Castilla y León n. ${ }^{\circ}$ 57, de 23 marzo 2011, precedido por el Programa Experimental de Teletrabajo en la Administración de la Comunidad de Castilla y León contemplado en la Orden $\mathrm{ADM} / 2154 / 2009$, de 17 de noviembre.

7 BO. País Vasco n. ${ }^{\circ} 111$, de 7 junio 2012, precedido por la Instrucción 1/2010, de 29 de octubre, que aprobó el Plan Piloto de Teletrabajo en la Administración General de la Comunidad Autónoma Vasca.

8 DO. Extremadura n. ${ }^{\circ} 135$, de 13 julio 2012.

9 BO. Illes Balears n. ${ }^{\circ}$ 91, de 29 junio 2013, precedido de las experiencias piloto en materia de teletrabajo aprobadas mediante las resoluciones del consejero de Interior de 20 de marzo de 2006 y de 4 de octubre de 2006. 
—en adelante, Decreto balear-; al Decreto n. ${ }^{\circ}$ 57/2013, de 12 de agosto, por el que se regula la prestación de servicios de los empleados públicos en régimen de teletrabajo en la Administración de Junta de Comunidades de Castilla-La Mancha ${ }^{10}$ —en adelante, Decreto castellanomanchego-; al Decreto n. ${ }^{\circ} 45 / 2013$, de 5 de diciembre, por el que se regula la prestación del servicio en la modalidad no presencial mediante la fórmula del teletrabajo para el personal funcionario y laboral al servicio de la Administración General de la Comunidad Autónoma de La Rioja y sus Organismos Autónomos ${ }^{11}$ —en adelante, Decreto riojano-; a la Orden de 20 de diciembre de 2013, conjunta de la Vicepresidencia y Consellería de Presidencia, Administraciones Públicas y Justicia y de la Consellería de Hacienda, por la que se regulan la acreditación, la jornada y el horario de trabajo, la flexibilidad horaria y el teletrabajo de los empleados públicos en el ámbito de la Administración general y del sector público de la Comunidad Autónoma de Galicia.—en adelante, Orden gallega- y la Resolución conjunta de 8 de agosto de 2014, de la Dirección General de Evaluación y Reforma Administrativa y de la Dirección General de la Función Pública, por la que se dictan las instrucciones relativas al desarrollo de la Orden de 20 de diciembre de 2013 por la que se regulan la acreditación, la jornada y el horario de trabajo, la flexibilidad horaria y el teletrabajo de los empleados públicos en el ámbito de la Administración general y del sector público de la Comunidad Autónoma de Galicia —en adelante, Resolución gallega-; a la Instrucción de 6 de agosto de 2014, del Director General de la Función Pública y Calidad de los Servicios, para la implantación del programa piloto de la modalidad de teletrabajo en la Administración de la Comunidad Autónoma de Aragón ${ }^{12}$ —en adelante, Instrucción aragonesa- y al Decreto n. ${ }^{\circ} 82 / 2016$, de 8 de julio del Consell, por el que se regula la prestación de servicios en régimen de teletrabajo del personal empleado público de la Administración de la Generalitat ${ }^{13}$ —en adelante, Decreto valenciano ${ }^{14}$.

10 DO. Castilla-La Mancha n. ${ }^{\circ}$ 158, de 16 agosto 2013.

11 BO. La Rioja n. ${ }^{\circ} 154$, de 13 diciembre 2013.

12 BO. Aragón n. ${ }^{\circ}$ 160, de 18 agosto 2014.

13 DO. Comunitat Valenciana n. ${ }^{\circ}$ 7828, de 14 julio 2016, precedido por la Instrucción de la Dirección General de Administración Autonómica de fecha 3 de diciembre de 2010, por el que se aprobó el programa experimental en materia de trabajo desde domicilio en el ámbito de la Administración de la Generalitat.

${ }_{14}$ No cae en el olvido la recientemente entrada en vigor Orden de 3 de octubre de 2016, de la Consejería de Hacienda y Administración Pública, por la que se convoca un proyecto piloto experimental de teletrabajo en la Administración Pública Regional (BO. Región de Murcia de 10 octubre 2016). Sin embargo, lo restringido de su ámbito de aplicación, ceñido al personal adscrito a la Secretaría General de la Consejería de Hacienda y Administración Pública, a la Intervención General, a la Dirección General de Patrimonio e Informática y a la Dirección General de la Función Pública y Calidad de los Servicios, desaconseja abordarla junto con las anteriores experiencias. 
En todas ellas se conviene en calificar el teletrabajo como modalidad de prestación de servicios ${ }^{15}$ construyendo su definición sobre dos elementos, cuales son el desarrollo de la prestación de trabajo fuera de las dependencias de la Administración y la utilización de las nuevas tecnologías de la información y de la comunicación ${ }^{16}$. Existe, no obstante, alguna norma que opta por describir el teletrabajo como "modalidad de jornada de trabajo» ${ }^{17}$, lo que parece aludir más al tiempo de trabajo que al desempeño del puesto de trabajo. Lo característico de todas las normas citadas es el desarrollo de la prestación fuera de los locales de la empleadora, aunque esta normativa asume que la misma se llevará a cabo en el domicilio del trabajador $^{18}$, lo cual no tendría que ser así necesariamente (Morgado, 2004: 1911). El Decreto valenciano, hace hincapié en que dicha modalidad de prestación de servicios se llevará a cabo "bajo la dirección, coordinación y supervisión de su superior jerárquico» (art. 2), destacando una subordinación por lo demás difuminada en una prestación caracterizada por la mayor independencia de quien la realiza.

Coincide también la normativa autonómica a la hora de determinar los objetivos perseguidos con la implantación del teletrabajo. En primer término, y puede que remarcando así su carácter preferente, se alude a la mejora en la organización del trabajo ${ }^{19}$ o a la consecución de una mayor eficiencia en la gestión pública $^{20}$ y en la prestación de los servicios, a través de una "mejor organización del trabajo» ${ }^{21}$ utilizado la tecnología. Se trata de objetivos cuyo alcance beneficia a la propia Administración, pero también al administrado y al trabajador. No por ello deja de hacerse cumplida referencia a la conciliación de la vida personal, familiar y laboral como principal aliciente para el trabajador ${ }^{22}$, con lo cual se pretende garantizarle "un mayor grado de satisfacción laboral»" ${ }^{23}$. En concreto, Precisa el preámbulo de la Instrucción aragonesa que la consecución de este bienestar a través de un adecuado equilibrio entre vida laboral y vida familiar es propia de «organizaciones saludables», entre las cuales las Administraciones Públicas deberían ocupar un lugar destacado.

Más ambiciosos son los objetivos contemplados en el Decreto extremeño, que ańade a los previamente citados otros como la modernización de la propia

15 Art. 13 de la Orden gallega. También el art. 1 del Decreto balear; el art. 2 del Decreto extremeño; el art. primero de la Instrucción aragonesa, así como el art. 1 del Decreto vasco, aunque en su preámbulo se aluda e ella como una «modalidad de prestación de la jornada de trabajo no presencial».

16 Así lo hace el art. 1 del Decreto castellanomanchego; el art. 3 del Decreto riojano el art. 13 de la Orden gallega y la Resolución gallega.

17 Art. 2.3 del Decreto castellanoleonés y art. 1 del Decreto vasco.

18 V. gr. el Decreto riojano (preámbulo, arts. 3, 4, 7, 8, 14, 15 y 18).

19 Art. 2.2 del Decreto castellanoleonés.

20 Art. 13 de la Orden gallega.

21 Art. 1 del Decreto vasco.

22 Art. 2.2 del Decreto castellanoleonés.

23 Art. 2.2 del Decreto castellanoleonés y art. 1 del Decreto vasco. 
Administración autonómica —expresión también utilizada por el art. 1 del Decreto de Illes Balears y por el preámbulo del Decreto castellanomanchego- a través de, entre otros medios, su digitalización y conectividad, definiendo así un modelo sostenible para los centros de trabajo. También se citan otros aspectos vinculados con la organización del trabajo en general, y con el incremento de la eficiencia de los trabajadores. Se alude así al aumento del compromiso y del nivel de motivación del personal, a la mejora de las condiciones de trabajo y la profesionalización de los empleados públicos como factores llamados a incrementar la calidad de los servicios. También a la potenciación del trabajo en términos de objetivos y resultados frente a criterios de mero cumplimiento del tiempo de presencia en el centro de trabajo - crítica evidente al modelo presencialista-, al aumento del compromiso con la calidad del trabajo, a la disminución del absentismo laboral, al aumento de la productividad y a la elaboración de métodos y sistemas de evaluación del desempeño de los empleados públicos. En suma, del espíritu de esta norma se desprende el ansia de lograr una mejor y más moderna organización del trabajo a través del uso de la tecnología y de la mayor eficacia y eficiencia en la relación con los ciudadanos usuarios de dichos servicios. La más reciente de las disposiciones citadas, a la sazón, el Decreto valenciano, alude en su preámbulo también a la flexibilidad en el tiempo de trabajo, que puede operar tanto en beneficio del empresario como del trabajador.

No quedan en el olvido intereses de otro orden, como la protección al medio ambiente o la distribución sostenible de la población, sobre los que habitualmente se omite cualquier mención expresa. Empero, se traen a colación en el preámbulo del Decreto extremeño, que define el teletrabajo como «medida orientada a la gestión más sostenible de los recursos y a la consecución de ahorro energético, de transporte y de otros consumos derivados de la actividad presenciali. En el mismo sentido se pronuncia el preámbulo del Decreto riojano. Por su parte, el del Decreto balear alude a los objetivos sociales que la correcta implantación del teletrabajo puede alcanzar a largo plazo, «como la disminución de la contaminación y el ahorro de energía avanzando en la línea de la responsabilidad social pública».

\subsection{2. Ámbito de aplicación}

En cuanto a su ámbito de aplicación, la normativa autonómica opta por desgranar un listado de puestos susceptibles de ser desempeñados en régimen de teletrabajo para, a renglón seguido, especificar ciertos casos donde expresamente se excluye esta posibilidad. Por lo general, éste se pone a disposición del personal funcionario, estatutario y laboral al servicio de la Administración de que se trate $\mathrm{o}$ de sus entidades públicas instrumentales ${ }^{24}$.

24 Así lo sostiene el art. 2 de la Orden gallega y el art. 3 del Decreto extremeño. Otras normas, como el Decreto castellanoleonés, se limitan a aludir a los organismos autónomos, entre dichas entidades públicas instrumentales. Por su parte, el Decreto balear incluye sólo al personal funcionario 
Diversos son los criterios acogidos por cada norma para excluir dicha posibilidad. Desde una perspectiva funcional, se conviene en excluir al personal que ocupe puestos de trabajo en oficinas de registro, atención e información al ciudadano, así como todos aquellos cuyas funciones conlleven necesariamente la prestación de servicios presenciales ${ }^{25}$. Por añadidura, en Galicia queda al margen de esta posibilidad el personal al servicio de la Administración de justicia, el que preste servicios en las instituciones sanitarias del Servicio Gallego de Salud y en centros docentes ${ }^{26}$. El art. 2.2 del Decreto riojano añade a estas tres exclusiones la que afecta a los empleados públicos que ocupen un puesto de Secretaría de Dirección General o de Secretaría General Técnica u órganos asimilados, a quienes no utilicen ningún tipo de herramienta informática en el desarrollo de las tareas encomendadas y a aquéllos que ocupen puestos de trabajo relacionados con servicios cuya prestación efectiva solamente queda plenamente garantizada con la presencia física del empleado público en el centro de trabajo. También se excluye al personal docente en el Decreto balear, así como al personal estatutario al servicio de la sanidad pública autonómica, al personal laboral de las entidades públicas empresariales, fundaciones, consorcios o sociedades mercantiles públicas del sector público de la Comunidad Autónoma de las Illes Balears. En Castilla y León, por el contrario, se incluye expresamente al personal docente, mientras que se excluye al personal que ocupe puestos de trabajo que lleven aparejadas funciones de dirección, coordinación o supervisión, iguales o superiores a Jefes de Servicio, y las Secretarías de Altos Cargos. Por su parte, el art. 3 del Decreto extremeño añade al listado habitual de supuestos excluidos los puestos de estructura cuya provisión se efectúe mediante el procedimiento de libre designación.

La voluntariedad que caracteriza la aplicación del teletrabajo en las Administraciones Públicas ${ }^{27}$ comporta que necesariamente su disfrute deba ser solicitado

representado en la Mesa Sectorial de Servicios Generales y al laboral de servicios generales que presta servicios en la Administración de la Comunidad Autónoma de las Illes Balears. El Decreto riojano alude al personal funcionario y al personal laboral que presta servicios en la Administración General de la Comunidad Autónoma de La Rioja y sus Organismos Autónomos (art. 2). Incluyendo en el programa piloto en ella regulado a todo "el personal funcionario, laboral o estatutario», véase el art. segundo de la Instrucción aragonesa, y citando simplemente al "personal empleado público», el art. 3 del Decreto valenciano. Más sucinto es el tenor literal del art. 3 del Decreto vasco, que hace referencia al personal funcionario incluido en el ámbito de aplicación del Acuerdo regulador de condiciones de trabajo del personal funcionario al servicio de la Administración de la Comunidad Autónoma de Euskadi y sus Organismos Autónomos y al personal laboral incluido en el ámbito de aplicación del Convenio de Colectivos Laborales al servicio de la Administración de la Comunidad Autónoma de Euskadi para los ańos 2010-2011. También el Decreto castellanomanchego extiende su ámbito de aplicación a los empleados públicos que presten servicios en la Administración de la Junta de Comunidades de Castilla-La Mancha y sus organismos autónomos (art. 2).

25 Paradigmático resulta lo dispuesto en el art. 3.2 del Decreto castellanoleonés.

26 Art. 2.3 de la Orden gallega.

27 Art. 2.2 del Decreto castellanoleonés; art. 1 del Decreto vasco; art. 5.2 del Decreto extremeño; art. 4 del Decreto castellanomanchego; art. 2 del Decreto balear; art. 4 del Decreto castella- 
por el personal. Para ello, no basta con que el solicitante esté en activo - aunque los Decretos balear, catellanoleonés y valenciano ${ }^{28}$ admiten que se pueda solicitar también desde cualquier situación administrativa que comporte reserva del puesto de trabajo [arts. 4.1.a), 5.a) y 5.1.a), respectivamente]-, sino que se exige que el potencial teletrabajador reúna una serie de características que denoten su pericia en el desempeño del puesto de trabajo en cuestión y unos conocimientos informáticos y telemáticos suficientes ${ }^{29}$. En concreto, se suele requerir que cuente con cierta antigüedad. Las Administraciones Públicas de Castilla y León, Aragón y Galicia la cifran en, al menos, dos años ${ }^{30}$, precisando, en el caso de la gallega, que la misma se ha de referir al servicio en el puesto para el que se solicita el teletrabajo, aunque se admite la acreditación de una experiencia por prestación de servicios en puestos con funciones y tareas análogas ${ }^{31}$. La Administración General de la Comunidad Autónoma de Euskadi y la de la Comunidad Valenciana flexibilizan este requisito, exigiendo que el personal haya desempeñado el puesto de trabajo durante períodos que sumen al menos un año, en los últimos dos años ${ }^{32}$. Por su parte, la Administración de la Comunidad Autónoma de Castilla-La Mancha cifra dicha antigüedad en un año [art. 5.b)]. Menos exigente todavía se muestra la Administración de la Comunidad Autónoma de Illes Balears, para la cual basta con acreditar un "desempeño efectivo minimo de seis meses en el puesto de trabajo que se pretende desarrollar mediante teletrabajo o en otro puesto con funciones análogas, siempre que en este último caso ya lleve un mes en el que ha de ejercer mediante teletrabajo" [art. 4.1.b)] ${ }^{33}$. En el extremo

noleonés; art. tercero de la Instrucción aragonesa; art. 2 del Decreto valenciano y art. 13 de la Orden gallega.

${ }^{28}$ Este último dispone que, de ser seleccionada, la persona solicitante ha de reincorporarse a su puesto de trabajo desde la situación administrativa en la que se encuentre, siendo excluida, de no solicitarlo, del procedimiento de selección.

29 Art. 5.1.c) del Decreto castellanoleonés; art. 5.4 del Decreto extremeńo; art. 14.e) de la Orden gallega. También lo exige el art. 5.1.e) del Decreto valenciano, que hace alusión en particular, a las medidas a adoptar para la protección de datos. Menos exigente se muestra el Decreto balear, para el cual bastará con que el solicitante realice una declaración responsable (art. 4.1). Incrementa el nivel de exigencia el art. 4.1.d) del Decreto vasco, conforme al cual podrá exigirse excepcionalmente la superación de una prueba

30 Art. 5 del Decreto castellanoleonés. En este caso, también se admite que se solicite desde la situación de excedencia concedida por esta Administración. Véase, asimismo, el art. 14.a) de la Orden gallega. En el mismo sentido, art. quinto de la Instrucción aragonesa que, a su vez, requiere de una antigüedad mínima de seis meses en el puesto de trabajo en cuestión.

31 Se entenderá que concurre dicha circunstancia aunque la prestación de los servicios haya sido interrumpida en los últimos cinco años, a tenor de la Quinta instrucción de la Resolución gallega.

32 Arts. 4.1.a) del Decreto vasco y 5.1.b) del Decreto valenciano.

33 En los supuestos en que la solicitud se haga desde alguna situación administrativa que comporte reserva de puesto de trabajo, una vez solicitado el reingreso al servicio activo, se debe acreditar que se desempeñó efectivamente el puesto reservado durante un mínimo de seis meses, si hace menos de tres años desde que dejó de cumplirlo. Si hace más de tres años, además, se tendrá que ocupar como mínimo el puesto tres meses, posteriormente al reingreso, antes de acceder a prestarlo en la modalidad de teletrabajo [art. 4.1.b)]. 
opuesto, está el Decreto riojano y el extremeño, que no exigen antigüedad alguna a los solicitantes.

El reconocimiento de este derecho se supedita también a la naturaleza y características del puesto de trabajo, que han de hacerlo susceptible de ser desempeñado de forma autónoma ${ }^{34}$ a distancia, a través de las nuevas tecnologías ${ }^{35}$.

34 Como recuerda la quinta instrucción de la Resolución gallega.

35 En concreto, el art. 14.c) de la Orden gallega, considera como tales «el estudio y análisis de proyectos, la elaboración de informes, la asesoría, la redacción y tratamiento de documentos, la inspección, la gestión de sistemas de información o el análisis y diseño de sistemas de información u otros análogos que no requieran la prestación de servicios presenciales», considerándose por tales aquéllos «en que la prestación efectiva sólo queda plenamente garantizada con la presencia física del/ de la empleado/a». La quinta instrucción la Resolución gallega ańade a los anteriores la elaboración de dictámenes o actas de inspección, la introducción de datos en bases de datos, y la traducción. Se excluyen de manera expresa aquéllos que comporten la presencia del trabajador, como los puestos de atención directa al público, los de oficinas de registros, aquéllos cuyas funciones conlleven la necesidad continua de consulta y manejo de documentación física que obre en poder de la Administración siempre que no quepa su consulta accediendo a las bases de datos de la unidad o a su escaneado, los puestos de personal conductor, subalterno, técnicos o administrativos de unidades con atención veinticuatro horas o los que desarrollen su jornada laboral, de manera permanente, fuera de las dependencias administrativas, como los agentes forestales, los guardacostas o similares. El art. 5.1.b) del Decreto castellanoleonés cita el estudio y análisis de proyectos, la elaboración de informes, las labores de asesoría, la redacción, corrección y tratamiento de documentos, la inspección, la gestión de sistemas de información y comunicaciones y el análisis, diseño y programación de sistemas de información y comunicaciones. A contrario sensu, excluye los puestos de trabajo en oficinas de registro, atención e información al ciudadano, así como todos aquéllos cuyas funciones conlleven necesariamente la prestación de servicios presenciales. Igualmente quedan excluidos los empleados públicos que ocupen puestos de trabajo que lleven aparejadas funciones de dirección, coordinación o supervisión, iguales o superiores a Jefes de Servicio, y las Secretarías de Altos Cargos. Sin ánimo de mencionar de nuevo supuestos ya aludidos, baste destacar que el Decreto extremeño ańade la grabación masiva de datos, el mantenimiento de sistemas de información y el tratamiento de información, entendiendo por esto último el procesamiento de datos y programación. El Decreto balear, por su parte, hace referencia también a quienes utilicen de manera continua y reiterada documentación oficial en papel que contenga datos confidenciales o protegidos por la normativa de protección de datos de carácter personal, así como a quienes ocupen puestos de trabajo que comporten funciones de dirección, coordinación o supervisión iguales o superiores a jefatura de servicio o asimiladas, y las secretarías de altos cargos. (art. 2). El Decreto castellanomanchego incluye la elaboración de propuestas de resolución y aquéllas relacionadas con la gestión de las tecnologías de la información y las comunicaciones y excluye expresamente las jefaturas de servicio de las unidades administrativas y aquellos cuyo desempeño requiera contactos personales frecuentes (art. 2.2). El Decreto riojano añade la gestión administrativa (como la solicitud de informes, elaboración de pliegos de contratación, elevación de propuestas, ejecución y control presupuestario, y similares), la redacción de memorias, la preparación de borradores de proyectos de disposiciones normativas o de actos administrativos generales, la actualización de registros informatizados, la compilación de información, la gestión de sistemas de información y comunicaciones y el análisis, diseño y programación de sistemas de información y comunicaciones. La Instrucción aragonesa excluye expresamente las actividades que, «en razón de los materiales o instrumentos utilizados en el desempeño de sus funciones» no puedan ejercerse en lugar distinto al centro de trabajo y aquellas para cuya ejecución se requiere la presencia física obligada en el lugar de desempeño habitual, citando a modo ejemplificativo las de conducción, mantenimiento, carreteras, cocina, campo, taller, limpieza o servicios auxiliares (art. quinto). El Decreto valenciano excluye, a diferencia de los citados, los puestos de naturaleza eventual, los puestos de personal no do- 
También acostumbra a ser requerida la disposición por parte del trabajador de los instrumentos de trabajo pertinentes, a la sazón, del equipo informático ${ }^{36}$. Sobre este extremo, detalla el art. 10 del Decreto castellanoleonés que dicho equipamiento consistirá en un ordenador personal que lleve incorporado el sistema de comunicación que defina la Administración «en función de la disponibilidad tecnológica y la seguridad de los sistemas", garantizando la accesibilidad, agilidad, seguridad y confidencialidad de la comunicación. Asimismo, corresponderá al personal empleado solucionar las incidencias que le resulten imputables en su equipo informático, previsión que comparte el Decreto castellanomanchego [art. 5.e)]. Con el propósito de mantener la comunicación entre la persona teletrabajadora y la Administración Pública, se prevé que ambos se faciliten mutuamente un número de teléfono de contacto, dándose por supuesto que los gastos inherentes a la adquisición, instalación y mantenimiento del terminal que corresponda al trabajador correrán a su cargo. En el mismo sentido se pronuncia el art. 11 del Decreto balear que, al menos, contempla la posibilidad de dirigirse al servicio de soporte informático de la dirección general competente en materia de innovación y desarrollo tecnológico, cuando las incidencias sean imputables a los sistemas de información de la Administración (art. 11.8) ) $^{37}$, así como art. 13 del Decreto extremeño. Este último, además, responsabiliza a quien teletrabaje de disponer de un espacio de trabajo adecuado a las funciones a desempeñar, En este caso, la Administración sólo se compromete a facilitar una cuenta de correo electrónico, las aplicaciones informáticas necesarias para el desarrollo de su labor cotidiana y un escritorio remoto, con acceso seguro VPN que reproduzca las condiciones de trabajo de un puesto físico del centro de destino. De modo más tajante, el art. 14. d) de la Orden gallega contempla la necesidad de que el personal disponga de un equipo informático básico con acceso a internet y acceso remoto a la red corporativa de la Xunta de Galicia ${ }^{38}$, de un lector de tarjeta, así como de teléfono móvil que «no serán facilitados, en ningún caso, por la Administración de la Xunta de Galicia», equipos cuyo mantenimiento y reparación incumbe también al empleado.

Sorprende que esta previsión se haya generalizado en la normativa autonómica reguladora del teletrabajo en la Administración — nótese que el Manual para la implantación de programas piloto de teletrabajo en la Administración

cente en centros docentes y en centros de formación e inserción profesional, pero también el personal de emergencias, los destinados en residencias y centros de atención a personas mayores dependientes o con diversidad funcional, centros de recepción y acogida de menores, centros de reeducación, comedores sociales, centros especializados de atención a mayores y centros de evaluación y orientación de discapacitados (art. 4).

36 Art. 5.1.d) del Decreto castellanoleonés; art. 4.1.e) del Decreto vasco y art. 15.2 del Decreto riojano.

37 Como también lo hace el Decreto riojano (art. 15.1).

38 A tenor de la susodicha instrucción quinta, que también prevé la posibilidad de realizar una prueba técnica. 
General del Estado dispone lo contrario, salvo pacto con el trabajador-, por ser contraria a la regla general contenida en el Acuerdo Marco Europeo sobre Teletrabajo, a tenor de la cual será el empresario quien deba facilitar, instalar y mantener los equipamientos necesarios para el teletrabajo, corriendo también con los costes vinculados a las comunicaciones, salvo que se haya acordado lo contrario. Huelga añadir que esta regla no es sino una manifestación de la ajenidad en los medios propia de la prestación de servicios objeto del Derecho del Trabajo (Thibault, 2000: 55 y Mella, 2003, 177), con arreglo a la cual incumbe al empleador proporcionar los instrumentos de trabajo. La cada vez más frecuente aportación de aquéllos por parte del trabajador (Mella, 2015: 175) confirma la transformación de las notas elementales de la prestación, que justifica el estudio de la implementación de las nuevas tecnologías como catalizador de dicho proceso. Conviene precisar que el Acuerdo Marco admite que se pacte la utilización del equipo propiedad del trabajador, excepción a la regla general que redunda en perjuicio del trabajador (Pérez de los Cobos, 2005: 1315).

En el polo opuesto se sitúan los Decreto vasco y valenciano, cuyos arts. 14 y 8.2 disponen que será la propia Administración la encargada de facilitar los recursos para el desempeño del puesto en la modalidad de teletrabajo, a saber: un ordenador portátil, un número de teléfono IP o móvil corporativo y el acceso a las aplicaciones informáticas del Departamento en cuestión, susceptibles de ser ejecutadas mediante el canal utilizado, en el caso de la Administración vasca; y un equipo informático, sin mayores precisiones, en cuanto concierne a la valenciana. En este último caso, sólo se prevé un intercambio de números de teléfono a fin de comunicarse posibles incidencias. Por su parte, incumbe al personal aportar una línea de acceso a Internet que cumpla con las características que defina la Administración ${ }^{39}$. El Decreto valenciano prohíbe expresamente el uso de redes de comunicaciones compartidas al público, habida cuenta del riesgo que entraña su uso, que pone en tela de juicio la confidencialidad y la protección de datos. Concretamente, alude a las conexiones a internet ofrecidas por «tiendas, hostelería, lugares públicos u otros tipo de establecimientos comerciales» y, en general, de aquellas, que el personal teletrabajador podría verse tentado a utilizar para ahorrarse unos costes que jamás debería haber recaído sobre su persona. De lo afirmado, es dable deducir que los gastos inherentes a la conexión serán a cargo del trabajador, aspecto digno de crítica, por cuanto supone un desplazamiento de los gastos requeridos para efectuar la prestación de servicios hacia el personal teletrabajador.

39 A mayores, se dispone que las personas teletrabajadoras dispondrán de una línea de atención telefónica receptora de incidencias sobre el servicio dentro del horario del mismo. La asistencia técnica para resolver incidencias relacionadas con el portátil o el teléfono, si requiere intervención técnica presencial, se realizará en los días de jornada presencial. 
También con arreglo esta última norma el personal teletrabajador ha de mantener incólume el equipo facilitado, de manera tal que, cuando una avería relativa al mismo o a sus aplicaciones impida la prestación de servicios no presencial y no pueda ser solventada ese mismo día, deberá incorporarse a su centro de trabajo al día siguiente. Es de advertir que esta previsión hace difícil la consecución de muchos de los objetivos inherentes a la implantación del teletrabajo, puesto que requiere una disponibilidad cuasi inmediata del personal para retornar a la prestación de servicios tradicional. Sobra añadir que eso puede ser harto difícil para quien ha solicitado ejecutar la prestación de servicios bajo la modalidad de teletrabajo para conciliar su vida personal, familiar y laboral, por problemas de salud o por graves inconvenientes vinculados al desplazamiento a las dependencias administrativas, por ejemplo.

Como presupuesto adicional a mencionar, el art. 4.1.c) del Decreto vasco requiere que el personal desarrolle, o tenga autorizada su solicitud para desarrollar, la jornada de trabajo a tiempo total o con una reducción de un octavo o un quinto, durante el tiempo en que se va a desarrollar el trabajo en la modalidad no presencial. Esta misma norma añade también una prohibición que afecta a quien esté realizando, o tenga autorizada la realización, de cursos presenciales de larga duración en horario laboral durante el tiempo en que se va a ejecutar el trabajo en la modalidad no presencial. Esta exclusión se justifica con fundamento en la incompatibilidad que presentan ambas actividades. No obstante, no se desestimará la solicitud por incumplimiento de este motivo cuando se trate de cursos de euskera que se imparten en una localidad próxima al lugar de teletrabajo (art. 4.1.g). Resta por recordar que el puesto de trabajo ha de ser susceptible de ser desempeñado mediante esta modalidad de prestación de servicios. A su vez, existen normas que requieren la superación de un curso formativo por parte del trabajador solicitante ${ }^{40}$.

\subsubsection{Procedimiento de selección}

La tramitación de las solicitudes depende de cada Administración Pública. En la Comunidad Autónoma de Euskadi, se dirigirán a los órganos competentes en materia de personal de los departamentos, entes u organismos autónomos a los que estén adscritos los empleados y empleadas solicitantes, dándose traslado de las que reúnan los requisitos exigidos a los órganos a los que estén adscritas orgánicamente las personas solicitantes para que, en el plazo de diez días, emitan informe sobre la solicitud. Ello se hará a la vista de la propuesta de la persona responsable de la unidad administrativa de la que dependa funcionalmente el solicitante sobre la cobertura de las necesidades del servicio. En caso de propuesta favorable, se indicará el número máximo de personas de su uni-

${ }^{40}$ Véase el art. 5.1.f) del Decreto valenciano. 
dad que podrían acceder al teletrabajo (art. 5 del Decreto). Además, el Área de Informática del departamento u organismo autónomo elaborará, en el plazo de diez días, un informe técnico sobre la necesidad de recursos telemáticos, la conectividad del lugar de teletrabajo, así como de la posibilidad de desarrollar sus funciones mediante este tipo de conexión con las prestaciones técnicas requeridas para ello ${ }^{41}$. A la vista de los informes del órgano al que está adscrito el empleado o empleada, y en el plazo de un mes desde la presentación de la solicitud, el órgano competente en materia de personal dictará resolución motivada de autorización o denegación de la solicitud de teletrabajo. Por razones organizativas, se prevé que la Administración pueda hacer convocatorias en las que se determinen las fechas para la presentación y resolución de las solicitudes y el inicio y fin de la prestación de servicio en modalidad no presencial (arts. 5. 3.4. y 5 del Decreto).

En la Comunidad Autónoma de Galicia, compete a la secretaría general, secretaría general técnica u órgano equivalente de las entidades públicas instrumentales del sector público (art. 15.3 de la Orden), que emitirán resolución en el plazo de tres meses contados a partir de la presentación de la solicitud, previo informe conjunto del centro directivo competente en materia de función pública y de evaluación y reforma administrativa, transcurrido el cual las solicitudes se entenderán estimadas. En cuanto al procedimiento, las personas interesadas deberán presentar su solicitud y la documentación pertinente ante el titular del centro directivo donde presten servicios, quien, en el plazo de quince días, deberá emitir un informe comprensivo de los siguientes extremos: a) sentido favorable o desfavorable —en este último supuesto, debidamente motivado- a petición de la persona interesada; b) cobertura de las necesidades del servicio; c) designación de un supervisor; d) asignación de tareas; y e) descripción de la forma y medios de llevar a cabo esta supervisión.

En la Rioja las solicitudes se dirigirán a la Secretaría General Técnica o Gerencia del Organismo Autónomo al que esté adscrito el empleado público solicitante, junto con un informe de su Jefe de servicio o equivalente superior jerárquico en el que se indicarán los objetivos que se establecerán al teletrabajador haciendo mención expresa de los medios técnicos con los que cuente en su domicilio (art. 8). Una vez presentada la solicitud, la Secretaría General Técnica o Gerencia del Organismo Autónomo correspondiente deberá remitir a la Dirección General competente en materia de Función Pública, en el plazo de un mes, la propuesta razonada de la Comisión de valoración de si procede estimarla

41 Cuando la persona solicitante haya prestado servicios en la modalidad de trabajo no presencial con anterioridad, los informes del órgano al que está adscrito ésta y del Área de Informática serán de ratificación de los emitidos en el procedimiento anterior y se emitirán en el plazo de cinco días, salvo que se hayan producido cambios en relación con la cobertura de las necesidades del servicio o con las necesidades de recursos telemáticos y viabilidad de la conectividad (art. 5.6 del Decreto vasco). 
o desestimarla, acompañada de la solicitud del empleado público, la documentación adjunta a la misma, los informes que estime oportunos que justifiquen la propuesta realizada y, en su caso, de la prelación determinada (art. 11). En dicha propuesta se ha de incluir el horario que se establece para el cumplimiento de la jornada en la modalidad de teletrabajo y la designación de la persona que actuará de supervisor. El plazo máximo para dictar y notificar la resolución será de tres meses desde la fecha de solicitud del empleado público.

En Castilla y León la solicitud se dirigirá al titular de la Secretaría General de la Consejería o al titular del órgano correspondiente del Organismo Autónomo, que dará traslado en el plazo de diez días hábiles a las Direcciones Generales, Delegaciones Territoriales u órganos equivalentes de los Organismos Autónomos en los que preste servicios el empleado público solicitante, a fin de que emitan el correspondiente informe en el plazo de veinte días, debiendo resolverse también en el plazo de tres meses (art. 4 de la Orden castellanoleonesa). Idéntico órgano será competente en Castilla-La Mancha, si bien el plazo para resolver será de un mes (art. 6 del Decreto castellanoleonés). En Extremadura también han de dirigirse las solicitudes a la Secretaría General, con sujeción al modelo de solicitud que se apruebe en el correspondiente Programa de Teletrabajo (art. 7 del Decreto extremeño), siendo el plazo para resolver de tres meses.

En la Comunidad Autónoma de Illes Balears la solicitud se dirigirá a la persona titular de la Secretaría General de la consejería o al órgano correspondiente del ente del sector público instrumental autonómico donde preste servicios el solicitante (art. 5 del Decreto balear). Dicha solicitud puede ir acompañada del informe del jefe de la unidad de trabajo de la cual dependa, con el visto bueno de la persona que sea su jefe de departamento, o jefe de servicio, si no hubiera. Si no se adjuntara el informe en cuestión, la Secretaría General o el órgano equivalente, en el plazo de cinco días hábiles, requerirá al jefe de la unidad de trabajo donde presta servicios la persona solicitante para que lo emita en el plazo de diez días hábiles (art. 6 del Decreto balear). El contenido del mismo hace referencia a la concurrencia de los requisitos exigidos para solicitar el desempeño del puesto de trabajo bajo la modalidad que nos ocupa, la cobertura adecuada de las necesidades del servicio, la indicación de la persona que actuará como supervisora, la distribución de la jornada y la aplicación de los criterios establecidos para conceder la solicitud, en caso de concurrencia de solicitantes. La persona titular de la consejería competente en materia de función pública ha de dictar y notificar una resolución motivada sobre la aceptación o denegación de la solicitud formulada en el plazo máximo de dos meses, a contar desde la solicitud de la persona interesada (art. 6.3).

Por su parte, en el programa piloto puesto en práctica por la Instrucción aragonesa, las solicitudes se dirigirán al Director General de la Función Pública y Calidad de los Servicios (art. sexto), mientras que el Decreto valenciano de- 
signa como competentes a las Subsecretarías u órganos competentes en materia de personal de las Consellerias u organismos proponentes, quienes analizarán las solicitudes y las valorarán de conformidad con el baremo previsto en el programa de teletrabajo, previo informe del órgano superior o directivo con competencias sobre el colectivo afectado (art. 14.2).

La conciliación vuelve a cobrar relevancia como finalidad de la implantación del teletrabajo en las Administraciones Públicas cuando, en el supuesto de existir varias solicitudes de teletrabajo en la misma unidad, se impone valorar preferentemente las solicitudes de las personas interesadas que cumplan los requisitos de flexibilización por razones de conciliación de la vida familiar y laboral, según la Orden gallega. Por su parte, el art. 6 del Decreto castellanoleonés dispone que, si por cuestiones de organización administrativa no fuera viable conceder la solicitud a todas ellas, agotadas las posibilidades de rotación o de acuerdo entre los empleados públicos y la Administración, se valorarán preferentemente las siguientes circunstancias debidamente acreditadas: a) que tengan a su cargo personas mayores de 65 años que precisen cuidados continuados, hijos menores de doce años, familiares hasta el segundo grado de consaguinidad o afinidad con discapacidad o familiares con enfermedad grave hasta el segundo grado de consaguinidad o afinidad ${ }^{42}$; b) que se trate de empleados públicos con discapacidad; c) que se trate de empleadas públicas víctimas de violencia de género; d) el tiempo y distancia de desplazamiento del domicilio al lugar de trabajo o la dificultad para acceder a un servicio o transporte público; e) la realización por parte de los empleados públicos de estudios reglados o relacionados con el puesto de trabajo y f) el no tener autorizada compatibilidad para el desempeño de un segundo puesto de trabajo, cargo o actividad en el sector público o privado. Similares criterios aporta el Decreto castellanomanchego que, en caso de empate, aboga por decantarse a favor del solicitante que ostente mayor antigüedad en el puesto de trabajo. El programa piloto regulado por la Instrucción aragonesa recomienda atender a la existencia de hijos, familiares o personas dependientes de personal, a la necesidad de cuidado de la propia salud, a necesidades derivadas de dificultades en la movilidad, de discapacidades físicas, psíquicas, sensoriales e intelectuales, a la distancia del domicilio habitual al centro de trabajo así como a situaciones puntuales de formación y capacitación (art. séptimo).

Parecidos son los criterios adoptados para el mismo fin por el Decreto vasco que, no obstante, dota su enumeración de una mayor claridad y sistematización, ordenándolos en cuatro categorías: a) aspectos relacionados con la salud laboral de la empleada o empleado público: discapacidades permanentes o tempo-

42 Las referencias que en este apartado se hacen al parentesco en grado de afinidad incluyen también el parentesco entre el empleado público y los parientes por consaguinidad de su pareja de hecho (art. 6.1 del Decreto castellanoleonés). 
rales; b) violencia de género; c) conciliación de la vida familiar y laboral ${ }^{43}$; d) tiempo y distancia de desplazamiento del domicilio al lugar de trabajo o dificultad para acceder a un servicio o transporte público para este desplazamiento; e) realización de estudios relacionados con el puesto de trabajo y f) realización de estudios reglados no relacionados con el puesto de trabajo o desarrollo de una actividad en el sector público o privado, para la que se tiene autorizada la compatibilidad (art. 6 del Decreto). Los mismos llevan asociados una puntuación a tener en cuenta a la hora de resolver la solicitud.

Similar es el sistema adoptado por el Decreto extremeño, que también desgrana una serie de circunstancias vinculadas a la conciliación de la vida personal y familiar, a la situación de violencia de género, al tiempo de desplazamiento al centro de trabajo, a la realización de estudios así como a la discapacidad y salud de la persona solicitante (art. 8) ${ }^{44}$. Es de advertir que su Disp. Ad. Primera reconoce una preferencia absoluta a favor de las trabajadoras en estado de gestación, finalizando la prestación de servicios en régimen de teletrabajo una vez hayan cesado las causas que la motivaron. Para la comprobación de los requisitos de los solicitantes y, en su caso, su valoración, se constituirá una comisión, cuya composición se adecuará al criterio de paridad entre hombres y mujeres, que, en todo caso, garantizará un adecuado perfil profesional ${ }^{45}$. Lo propio hace el Decreto riojano, que enumera entre los criterios a considerar los vinculados a la conciliación entre la vida personal y laboral, la discapacidad, la situación de violencia de género, el tiempo y distancia de desplazamiento del domicilio al lugar de trabajo o la dificultad para acceder a un servicio de transporte público, la realización por parte del empleado público de estudios reglados o relacionados con el puesto de trabajo, su permanencia en la Administración así como los medios técnicos con que cuente en su domicilio (art. 7).

43 Entre los cuales se detallan a) el tener, por razones de guarda legal, a su cuidado directo algún o alguna menor de doce años o persona discapacitada física, psíquica o sensorial que no desempeńe actividad retribuida o familiar que padezca enfermedad grave continuada y conviva con el mismo o b) el tener que atender o cuidar a un familiar hasta el segundo grado de consanguinidad o afinidad, o incluso de grado más lejano si mediara convivencia, por tener dificultades de movilidad o padecer una enfermedad grave continuada, acreditada por informe médico.

${ }^{44}$ En caso de igualdad en la puntuación total, se desempatará, sucesivamente, por la mayor puntuación obtenida en los distintos apartados en el orden en que están indicados. De persistir, se resolverá por sorteo público.

${ }_{45}$ La misma estará constituida por la persona titular de la Dirección General de la Función Pública, Recursos Humanos e Inspección o persona que la sustituya, que actuará a la sazón como Presidente; un representante de la Dirección General de la Función Pública, Recursos Humanos e Inspección, un representante de la Dirección General de Administración Electrónica y Evaluación y un representante de la Consejería afectada por el Programa de Teletrabajo aprobado en cada caso, en calidad de vocales y un funcionario de la Consejería de Administración Pública como Secretario, con voz y voto. Además, podrán asistir a las reuniones, con voz y sin voto, un representante de cada una de las organizaciones sindicales con representación en la Mesa Sectorial de Administración General. 
El Decreto balear exige agotar las posibilidades de rotación, de turnicidad o de acuerdo entre las personas solicitantes, tras lo cual se autorizará a quien no haya tenido concedida, durante los dieciocho meses consecutivos inmediatamente anteriores, la prestación de servicios mediante la modalidad de teletrabajo. Si todos los solicitantes ya la han disfrutado, el reconocimiento del derecho se resolverá, una vez más, acudiendo a una serie de criterios vinculados a la conciliación de la vida familiar y personal con la laboral, a la situación de discapacidad o alteración de la salud que afecte a la movilidad, a la situación de violencia de género, a la realización de estudios reglados relacionados con el puesto de trabajo o a la distancia de desplazamiento del domicilio al puesto de trabajo. Coinciden con los supuestos anteriores en llevar aparejada cierta puntuación, de manera tal que quien alcance una suma mayor ostentará un derecho preferente a que le sea concedida su solicitud. Es de notar el detalle con el que se define cada uno de estos supuestos ${ }^{46}$.

Por último, el Decreto valenciano se remite al programa de teletrabajo, que será el encargado de fijar el baremo aplicable a la selección del personal, que deberá ajustarse a los enumerados en su Anexo II, que alude a causas vinculadas con la conciliación, la diversidad funcional del solicitante y la distancia entre el lugar de trabajo y su domicilio.

\subsubsection{Contenido de la prestación}

Para evitar que el teletrabajo produzca desarraigo «o un cambio de hábitos y rutinas de tal magnitud que la vuelta a la modalidad presencial pueda causar algún perjuicio a la persona empleada» (art. 8 del Decreto vasco), la normativa vasca, extremeña, balear ${ }^{47}$, valenciana y gallega establecen un límite temporal de un año, sin perjuicio de su prórroga si persisten las mismas condiciones que hayan motivado su concesión, en la Comunidad Autónoma de Galicia y en la Comunidad Valenciana ${ }^{48}$. Por su parte, los Decretos vasco y extremeño preceptúan que el tiempo mínimo entre períodos de teletrabajo ha de ser de seis meses ${ }^{49}$, si bien en el primero, "por razones de urgencia y necesidad de la prestación del servicio se permite la autorización de nuevos periodos de teletrabajo antes de que haya transcurrido este tiempo minimo, de una duración no superior a dos meses. Por su

46 Véase art. 7.4 del Decreto balear.

47 Con arreglo al art. 8.2 del Decreto balear, «la autorización por tiempo inferior a un año se irá prorrogando automáticamente por meses, a menos que la persona autorizada comunique, antes de finalizar el plazo inicialmente autorizado o de prórroga, la voluntad de reincorporarse a la modalidad presencial al acabar el mismo».

48 A tal efecto, la persona que teletrabaje solicitará su prórroga con una antelación mínima de dos meses a la fecha de finalización. No será necesaria la presentación del cuestionario relativo a la información de riesgos en el teletrabajo ni del test de autoevaluación de riesgos laborales siempre y cuando se mantengan las circunstancias descritas en ellos (instrucción quinta).

49 Véase art. 4 del Decreto extremeño. 
parte, el Decreto castellanomanchego permite su autorización «por tiempo indefinido» (art. 6.4). El programa piloto implantado por la Instrucción aragonesa prevé experiencias más breves, de tres meses de duración, aunque dichos períodos son susceptibles de prórroga, sin que se fije un límite máximo expresamente.

El Decreto balear añade a ese período máximo uno mínimo, de seis meses (art. 9), lo que se compadece mal con la voluntariedad de la prestación de servicios bajo esta modalidad, salvo que se entienda que el trabajador conserva el derecho a revertir su situación sin que haya transcurrido dicho semestre. Sin embargo, la exigencia de acreditar una causa justificativa (art. 14.3 del Decreto) para poder retornar al trabajo presencial antes de la fecha de finalización prevista $^{50}$ desmiente que en este caso el teletrabajo constituya una modalidad libremente reversible. También flexibiliza el límite máximo, previendo que después de un año se pueda prorrogar la autorización como máximo hasta dieciocho meses en total, previa solicitud de la persona interesada, "siempre que se mantengan los requisitos y previa nueva evaluación de los criterios preferentes de autorización». Además, la persona interesada podrá solicitar la nueva autorización al menos dos meses antes de finalizar los dieciocho meses sin que se tenga que producir la interrupción de la prestación con esta modalidad.

En cuanto atañe a la forma en la cual se desarrollará la prestación de servicios, se advierte que las funciones no serán otras que las que el trabajador venía desempeñando en su puesto de trabajo habitual, "salvo las ligadas a la presencia física en las dependencias administrativas» (art. 15.3 de la Orden gallega). La pluralidad de normas examinadas conviene en regular una prestación en la modalidad de teletrabajo llevada a cabo en alternancia con el trabajo presencial. El Decreto balear impide que se puedan efectuar más de tres jornadas semanales en régimen de teletrabajo (art. 9.1). La Orden gallega comparte dicha regla y, además, impide que las jornadas sean consecutivas, salvo que así lo requieran las necesidades del servicio y así se haga constar en el informe emitido por el centro directivo. Por su parte, el Decreto castellanoleonés y el valenciano (art. 7.1 $)^{51}$ preceptúan que la jornada de trabajo se distribuya de manera que al menos tres días a la semana se presten de forma no presencial. El Decreto vasco también dispone el desempeño de la prestación de manera no presencial durante tres días, y de manera presencial en los dos restantes (art. 8.2). Las cuatro

50 Solicitud que ha de realizarse con un preaviso mínimo de quince días. Una vez acreditada la causa alegada, se dictará una resolución motivada de finalización de la prestación del servicio en la modalidad de teletrabajo.

51 Aunque el valenciano se remita a lo dispuesto en el programa concreto de teletrabajo que, atendiendo a las características específicas de los puestos de trabajo, establecerá la distribución de la jornada y el sistema de control concretos, sin que en ningún caso el número de días de modalidad presencial pueda ser inferior a dos (art. 7.3). No obstante, se advierte que siempre debe existir un porcentaje del tiempo de trabajo, determinado en el programa de teletrabajo, no inferior al veinte por ciento, de la prestación de servicios de modo presencial, 
normas rechazan que la jornada diaria pueda fraccionarse en ambas modalida$\operatorname{des}^{52}$. El Decreto extremeño fija directamente en tres los días semanales destinados a la prestación de servicios no presencial, (art. 4.2), si bien permite a las trabajadoras en estado de gestación la prestación del total de la jornada en régimen de teletrabajo (Disp. Ad. Primera). También prevé la posibilidad de cumplir la totalidad de la jornada en régimen de teletrabajo el Decreto castellanoleonés (Disp. Ad. 1.a), ante situaciones de alerta sanitaria, $u$ otros acontecimientos de carácter extraordinario, volviendo a alternarla con la prestación presencial cuando hayan cesado dichas causas.

Más flexible se muestra el Decreto castellanomanchego, a tenor del cual «el porcentaje de jornada de teletrabajo nunca podrá ser superior al cuarenta por ciento de la jornada de trabajo en cómputo mensual, siendo obligada la asistencia presencial al puesto de trabajo el tiempo restante» (art. 3.2). Al amparo de esta normativa tampoco cabrá fraccionar la jornada diaria entre sendas modalidades, pero nada impide que se teletrabaje hasta alcanzar el porcentaje máximo sin solución de continuidad (art. 3.1). También el Decreto riojano ofrece un marco normativo maleable al permitir desempeñar entre un veinte y un cuarenta por ciento de la jornada de forma no presencial (art. 14.1) ${ }^{53}$. Cruzando ese límite, la Instrucción aragonesa permite que, en el marco del plan piloto que regula, el tiempo dedicado a la prestación de servicios bajo la modalidad de teletrabajo pueda llegar al cincuenta por ciento de la jornada total en cómputo semanal. La distribución concreta de ese horario se acordará entre el teletrabajador y su supervisor directo, pudiendo ser por días completos, en cuyo caso se limitará a un máximo de dos días por semana, o en una parte de la jornada diaria (art. cuarto).

Para evitar el aislamiento entre los diversos miembros del personal y propiciar las sinergias que contribuyen a la eficiencia de cualquier organización, el Decreto valenciano dispone, con buen criterio, que al menos un día a la semana coincida toda la plantilla en las dependencias físicas (art. 7.5). Asimismo, por necesidades del servicio debidamente justificadas, podrá ser requerida la presencia en el centro de trabajo del personal que preste servicios en la modalidad de teletrabajo con una antelación mínima de veinticuatro horas (art. 7.6 del Decreto valenciano). Con idéntico propósito, el Decreto vasco (art. 8.2) preceptúa que uno de los días en los que la prestación sea presencial se dedique a reu-

52 Art. 8.1. del Decreto castellanoleonés; art. 8.2 del Decreto vasco; art. 9 del Decreto balear y art. 7 del Decreto valenciano.

$53 \mathrm{La}$ jornada ordinaria está establecida en treinta y siete horas y media semanales de trabajo efectivo, por lo que, el veinte por ciento de la jornada laboral semanal supone un total de siete horas y media y el cuarenta un total de quince horas. A su vez, entre las siete horas y media y las quince horas semanales, se puede establecer la acumulación en uno o dos días completos semanales, o su distribución irregular a lo largo de la semana que podrán disfrutarse bien al inicio, bien al final de la jornada; de ocho a diez y media de la mańana y de la una a las tres y media de la tarde para empleados que realicen jornada continuada. 
niones de coordinación, formación, participación en proyectos comunes u otras cuestiones que determine la persona responsable de la unidad administrativa, que será además la encargada de fijarlo (art. 8.2).

Además, la Orden gallega impone, durante la jornada dedicada al teletrabajo, un deber de presencia virtual, en virtud del cual ha de tener activado el correo corporativo y el teléfono móvil, pudiendo ser requerida su presencia en las dependencias administrativas si así fuera preciso por las necesidades del servicio. A tal fin, se señalará el horario en que el personal deberá estar disponible en la resolución de concesión ${ }^{54}$. En idéntico sentido, merece especial mención lo dispuesto en los arts. 8.5 del Decreto vasco y 7.1 del valenciano, cuando contemplan la posibilidad de fijar períodos mínimos de interconexión para la realización del trabajo, pudiendo hacerse coincidir con unas franjas horarias determinadas, en las que las necesidades del servicio hacen necesaria la comunicación entre la Administración y la persona teletrabajadora. Ciertamente, concurren razones organizativas que avalan la previsión de estos períodos de conexión, mas no deja de echarse en falta la regulación de períodos de desconexión, durante los cuales el trabajador tenga el derecho-deber de desconectar (Mella, 2016: 30) y apartarse del trabajo, habida cuenta del riesgo que el teletrabajo entrańa para aquellos trabajadores propensos a padecer cierta adicción al trabajo (Pérez de los Cobos y Thibault, 2001, 80; y Mella, 1998: 663).

A fin de garantizar la correcta prestación de servicios de los empleados públicos que opten por el teletrabajo, también resulta común la previsión de actividades formativas especialmente dirigidas a estos trabajadores, aunque únicamente la norma vasca y la riojana configuran su superación como un requisito necesario para acceder a la prestación de servicios en esta modalidad no presencial $^{55}$. En su momento, el Decreto castellanoleonés ya encomendó a la Escuela de Administración Pública de Castilla y León la tarea de facilitar al personal empleado la formación relativa al desempeño de la jornada de trabajo no presencial, así a la prevención de riesgos laborales. La misma competencia ha sido atribuida al Instituto Vasco de Administración Pública, quien también ha de formar al personal teletrabajador sobre protección de datos de carácter personal ${ }^{56}$. También la Escuela Gallega de Administración Pública llevará a cabo actividades formativas al respecto. De cara al teletrabajador, éstas incidirán en materias tales la protección de datos, la confidencialidad, los soportes telemáticos a emplear y la prevención de riesgos laborales. Es menester hacer hincapié en esta última, ya que al teletrabajador se le impone el deber de cumplir la normativa

54 Instrucción quinta.

55 Art. 4.1.f) del Decreto vasco, que supedita su concesión a la superación de los cursos de formación del Instituto Vasco de Administración Pública relativos a la prestación del servicio en la modalidad no presencial. Cfr. art. del Decreto riojano.

56 Art. 17 del Decreto vasco. 
en materia de seguridad y salud laboral, para lo cual se le facilita a través de la intranet un "Manual de información para teletrabajador o teletrabajadora", al cual convendría añadir de manera preceptiva formación específica y personalizada.

Se sostiene esta posición, por más que a la solicitud deba adjuntarse un cuestionario relativo a la autoevaluación de riesgos laborales en el teletrabajo ${ }^{57}$ amén de una declaración relativa a la información de riesgos laborales en el teletrabajo. Ésta implica el compromiso de adoptar las medidas de seguridad e higiene contenidas en el citado Manual y las que, en su caso, recomiende el Servicio de Riesgos Laborales una vez evaluado el cuestionario de autoevaluación (sic.) ${ }^{58}$. A fin de facilitar dicha tarea, el Servicio de Prevención de Riesgos Laborales prestará asesoramiento telefónico, cuando así se precise. Asimismo, la norma gallega prevé la posibilidad de acordar una inspección presencial en el domicilio del trabajador, previa autorización, habida cuenta de la especial protección de la que es acreedor el ámbito donde se ejecuta la prestación de servicios, inviolable, a fin de proteger la intimidad del trabajador y de su familia (Mella, 2015: 179).

También la norma balear hace descansar sobre el personal buena parte de la actividad preventiva, previa información recibida de la propia Administración relativa a la política en materia de salud y seguridad en el trabajo, especialmente sobre las exigencias relativas a las pantallas de datos. Es la persona autorizada la encargada de rellenar el cuestionario de autocomprobación en materia de prevención de riesgos laborales para el puesto de teletrabajo facilitado por el servicio competente en materia de seguridad y salud laboral de los empleados públicos de la Administración de la Comunidad Autónoma de las Illes Balears (art. 11.5 del Decreto balear). La exigencia de dicho cuestionario también concurre en el Decreto valenciano (art. 9.1), que prevé, no obstante, la solicitud de una inspección domiciliaria, voluntaria, por las razones arriba indicadas.

La norma vasca, por su parte, prevé que el Servicio de Prevención de Riesgos Laborales «facilite» al personal la evaluación de riesgos de su actividad, así como la formación e información necesaria en materia de seguridad y salud laboral para evitar dichos riesgos o, de ser inevitables, «minimizarlos y disponer la aplicación de las medidas preventivas necesarias» (art. 16). A tal efecto, se centra la atención en la formación del personal, que deberá acudir a una sesión donde se le indicará como debe acondicionar su puesto de trabajo fuera de las dependencias administrativas, y se le ilustrará sobre las nociones necesarias sobre seguridad y ergonomía en los puestos de trabajo con pantallas de visualiza-

57 También solicitado por el art. 10.7 del Decreto castellanoleonés, donde se dispone que «los empleados deberán cumplimentar el cuestionario de autocomprobación en materia de prevención de riesgos laborales para el puesto de teletrabajo facilitado por el Servicio competente en materia de Seguridad y Salud Laboral de los empleados públicos de la Administración de la Comunidad de Castilla y León».

58 Instrucción quinta. 
ción de datos, conocimientos cuya adquisición deberá acreditar a través de un prueba. También aquí se reconoce el derecho de las personas teletrabajadoras a solicitar al Servicio de Prevención el examen del puesto de trabajo en su lugar de teletrabajo. No obstante, el relevante rol del trabajador en la aplicación de la normativa en materia de seguridad y salud en el trabajo (Mella, 2015: 175) se evidencia cuando se advierte que, en el caso de que el Servicio de Prevención recomiende adoptar medidas correctoras en el puesto de trabajo, será responsabilidad del personal teletrabajador su implantación.

De menor calado parece la competencia formativa atribuida a la Escuela Balear de Administración Pública, que acreditará el correcto cumplimentado por el personal de un cuestionario relativo las formas de cumplimiento de la jornada de trabajo no presencial, evaluación por objetivos, prevención en riesgos laborales, protección de datos, seguridad informática y confidencialidad administrativa. Ello se hará previa puesta a disposición de un «manual de teletrabajo» donde se recogerán los contenidos objeto de evaluación, cuestionario que se tendrá que rellenar antes de empezar cada nuevo período en la modalidad de teletrabajo (art. 12 del Decreto balear).

Más lacónico todavía se muestra el Decreto castellanoleonés, cuando atribuye a la Administración la competencia para facilitar al personal empleado público la formación necesaria para la prestación de servicios mediante teletrabajo, así como a las personas responsables de las unidades administrativas la formación necesaria en técnicas de dirección por objetivos, planificación y gestión (art. 4.4).

Procede hacer alusión también a las competencias formativas atribuidas a la Escuela Riojana de Administración Pública (art. 19 del Decreto riojano), que ha de impartir un curso destinado al personal autorizado a teletrabajar con un contenido similar a los citados anteriormente, curso cuya realización se tendrá en cuenta en futuros períodos de teletrabajo ${ }^{59}$. Aunque la Instrucción aragonesa

59 También el Decreto riojano atribuye al Servicio de Prevención de Riesgos Laborales el deber de facilitar al personal «la evaluación de riesgos de su actividad, así como la información necesaria en materia de seguridad y salud laboral para evitar los riesgos laborales o, si son inevitables, minimizarlos y disponer la aplicación de las medidas preventivas necesarias». Por su parte, el personal ha de acudir a una sesión formativa donde se le indicará como debe acondicionar su puesto de trabajo fuera de las dependencias administrativas, así como las nociones necesarias sobre seguridad y ergonomía en los puestos de trabajo con pantallas de visualización de datos, sesión de preceptiva asistencia, debiendo las personas empleadas acreditar los conocimientos adquiridos mediante la prueba correspondiente (art. 18). No obstante, el Servicio de Prevención les proporcionará asistencia y asesoramiento telefónico cuando lo precisen. Igualmente, los empleados públicos teletrabajadores podrán solicitar al Servicio de Prevención de Riesgos Labores el examen del puesto de trabajo en su domicilio particular. Se accederá a esa petición cuando el Servicio considere que es necesaria esa presencia domiciliaria. En el caso de que el Servicio de Prevención recomiende adoptar medidas correctoras en el puesto de trabajo, será responsabilidad del personal teletrabajador su implantación. 
también contempla la recepción de formación por parte de los sujetos involucra$\operatorname{dos}^{60}$ — teletrabajadores y supervisores_- no señala órgano alguno encargado de tal cometido, como tampoco lo hace el Decreto valenciano (art. 10).

Pensando en el personal responsable de los quienes presten servicios bajo esta modalidad, se prevé facilitar una formación orientada hacia técnicas de dirección destinadas a evaluar el desempeño con base en la consecución de determinados objetivos $^{61}$. Este aspecto adquiere especial relevancia, toda vez que la propia normativa, como la instrucción quinta de la Resolución gallega, recuerda que los trabajadores ejecutarán su prestación "por objetivos, según las tareas que sean encomendadas por la persona supervisora, que será la responsable de verificar su adecuado desempeño a través de los indicadores acordados y de los medios de seguimiento de la actividad que se establezcan». En concreto, el Decreto vasco añade que las tareas a realizar y los resultados a obtener durante el desarrollo de la jornada de trabajo bajo la modalidad no presencial «se fijará por acuerdo entre la persona responsable de la unidad administrativa y el empleado o empleada», otorgando así una mayor participación a la persona trabajadora. En caso de desacuerdo, resolverá el órgano al que esté adscrita la persona empleada, siguiendo los criterios que establezca al respecto la Dirección de Relaciones Laborales (art. 9). Aunque su escaso poder de negociación impide que esta precisión se erija en garantía del carácter razonable de los objetivos fijados, no deja de constituir un avance en el participación de la persona trabajadora en la organización del trabajo. El Decreto balear, por su parte, sólo prevé la puesta a disposición de un manual relativo a técnicas de evaluación, dirección por objetivos, planificación y gestión y formas de cumplir la jornada de trabajo no presencial (art. 12.2).

Siendo la reversibilidad ${ }^{62}$ en la adopción del teletrabajo una característica del mismo — salvo lo dispuesto en el Decreto balear (art. 14)_, correlato de la voluntariedad de su solicitud ${ }^{63}$, ha de garantizarse el retorno a la prestación de ser-

${ }^{60} \mathrm{Su}$ art. octavo contempla la necesidad de deparar formación en teletrabajo, manejo de las herramientas informáticas y de telecomunicaciones que vayan a utilizarse durante la realización del programa piloto, medidas necesarias de protección de la salud y prevención de riesgos laborales en el puesto de trabajo, protección y confidencialidad de datos, establecimiento y evaluación de objetivos y resultados y gestión eficaz del tiempo.

${ }^{61}$ Art. 11 del Decreto castellanoleonés: art. 19 del Decreto riojano; art. 16 de la Orden gallega y art. 17 del Decreto vasco. También se prevé facilitar acciones formativas a los responsables en el art. 12 del Decreto extremeño, cuyo seguimiento será obligatorio.

${ }^{62}$ A la que alude de manera directa el art. 5 del Decreto extremeño, sí como del art. 4 del Decreto riojano. Este último requiere que la renuncia sea comunicada «a la Secretaría General Técnica o Gerencia del Organismo Autónomo al que este adscrito el teletrabajador, quien la remitirá en un plazo no superior a diez días al titular de la Dirección General competente en materia de función pública, junto con una propuesta de fecha de incorporación del teletrabajador a la modalidad presencial» (art. 13).

63 Aunque el Decreto valenciano exija que medie comunicación de la persona teletrabajadora, con un preaviso mínimo de quince días, no deja de tratarse de un requisito formal que no empece el carácter voluntario del teletrabajo (art. 11). 
vicios presencial a instancia del trabajador. Además de por su propia voluntad, la prestación de servicios en régimen de teletrabajo se podrá revertir por causas tales como las necesidades del servicio, el incumplimiento de los objetivos establecidos así como por circunstancias sobrevenidas que alteren sustancialmente las condiciones y los requisitos que motivaron la resolución de autorización ${ }^{64}$. El cambio de puesto de trabajo supondrá también la pérdida del derecho al teletrabajo con arreglo a la normativa gallega ${ }^{65}$, y el mutuo acuerdo de la partes ${ }^{66}$. El Decreto vasco prevé también la posibilidad de suspender temporalmente la prestación de servicio en la modalidad de trabajo no presencial "por circunstancias sobrevenidas que afecten a la persona empleada o a las necesidades del servicio que justifiquen la medida» (art. 11) ${ }^{67}$.

Expuestos las singularidades de la regulación autonómica que se han considerado dignas de mención, huelga añadir que el personal teletrabajador tendrá los mismos derechos y deberes que el que desempeñe sus funciones en régimen íntegramente presencial, sin que pueda sufrir variación alguna en sus retribuciones. Aunque algunas normas se ocupan de subrayar este extremo ${ }^{68}$, en la práctica la prestación de servicios en régimen de teletrabajo comporta desventajas que convendría superar. A modo de ejemplo, es de advertir que el desplazamiento de costes a que da pie la aportación y mantenimiento del material informático y el sostenimiento de la conexión a la red por parte de quienes desarrollen sus funciones bajo esta modalidad comportan una notable minoración indirecta de las retribuciones a percibir, frente a lo cual no los protege esta normativa.

${ }^{64}$ Se dispone que la resolución por la que se modifique o revoque la autorización de la prestación de servicios en régimen de teletrabajo deberá ser comunicada con una antelación mínima de quince días naturales (art. 15.4 de la Orden gallega). Véase también el art. 4.4 del Decreto castellanoleonés, que exige audiencia previa del personal afectado y el art. 7.1 del Decreto castellanoleonés. No obstante, este último dispone que "la autorización quedará asimismo sin efecto por la finalización del plazo establecido, en su caso, o por cese en el puesto de trabajo. Sin embargo, en el caso de cese en el puesto de trabajo como consecuencia de un cambio de puesto, el órgano competente podrá autorizar la continuidad de la prestación de servicios en régimen de teletrabajo si el nuevo puesto es de similares características al anterior y siempre que sea susceptible de prestación en régimen de teletrabajo.

65 Instrucción quinta.

66 Art. 12.1.d) del Decreto vasco.

67 En la tramitación del procedimiento se dará audiencia a la persona afectada. Acreditadas las circunstancias justificativas, el órgano competente en materia de personal dictará resolución motivada de suspensión de la autorización, en la que se señalará el plazo de suspensión (art. 11).

68 Véase el art. 9 del Decreto castellanoleonés y art. 10 del Decreto vasco. 


\section{Conclusión}

El desarrollo de las nuevas tecnologías de la información y de la comunicación ha hecho que éstas trascendieran su rol instrumental, erigiéndose en catalizadores de la evolución de la prestación de trabajo. Esta transformación afecta notablemente a aquellos puestos de trabajo para cuyo desempeño se requiere una mayor autonomía funcional y una formación especializada, puestos que abundan en el sector privado, pero no menos en las Administraciones Públicas. Lamentablemente, la implementación de nuevas formas de trabajo no presencial basadas en el uso de las nuevas tecnologías, como el teletrabajo, no goza todavía de reflejo en el EBEP, tras cuya refundición se ha perdido una oportunidad para diseñar un marco jurídico a partir del cual regular el teletrabajo en las diversas Administraciones Públicas.

Frente a la inactividad del legislador estatal, merecen una favorable acogida las experiencias llevadas a cabo a nivel autonómico. Diversas han sido las Comunidades Autónomas que, en ejercicio de sus competencias, han regulado la prestación de servicios no presencial a través del teletrabajo del personal al servicio de sus respectivas Administraciones. Pese a ofrecer una regulación sistemática del teletrabajo, estas normas muestran algunos extremos susceptibles de mejora. En primer término, todas ellas coinciden en identificar el teletrabajo con aquél desarrollado desde el domicilio del trabajador, pese que éste no es sino una especie perteneciente a un género que comprende todo aquel trabajo no presencial basado en el uso de las nuevas tecnologías. Lo limitado de su ámbito se comprende mejor al abordar la finalidad de dichas normas, que comparten el afán de propiciar la conciliación de la vida personal, familiar y laboral. Siendo este un loable objetivo, convendría plantearse la regulación de otras modalidades de teletrabajo, amén de la prosecución de otros objetivos de interés social, tales como la protección del medio ambiente, la redistribución de la población o la prevención de accidentes y molestias derivados del exceso de tráfico de vehículos a motor.

En cuanto al régimen jurídico de la prestación, procede alabar la regulación de aspectos tales como el establecimiento de límites temporales que regulan la alternancia del teletrabajo con la prestación de servicios presencial, a fin de evitar el aislamiento del trabajador, si bien se echa de menos la previsión generalizada de causas debidamente justificadas que permitan, de manera temporal, una prestación desempeñada íntegramente a distancia. Por el contrario, urge replantearse la asunción de los costes inherentes al teletrabajo por parte del personal empleado público, so pena de convertir esta modalidad de prestación de servicios en un paradigma de precariedad. La previsión de actividades formativas de asistencia preceptiva se considera también un extremo a incluir, habida cuenta de la responsabilidad que asume el personal en materias como la protección de datos de carácter personal o la prevención de riesgos laborales. Aunque ya exis- 
tan normas que hayan hecho suyas estas propuestas, convendría tenerlas presentes de cara a la reforma de las normas autonómicas vigentes, pero también con vistas al diseño de un marco general regulador del teletrabajo en las Administraciones Públicas.

\section{Bibliografía}

Belzunegui Eraso, Ángel (2008): «Teletrabajo en España, acuerdo marco y administración pública», Revista Internacional de Organizaciones, 1, 129-148.

Ferreiro Regueiro, Consuelo (2015): «La conformación del teletrabajo en la negociación colectiva», en Mella Méndez, Lourdes (dir.) y Villalba Sánchez, Alicia (coord.), Trabajo a distancia y teletrabajo. Estudios sobre su régimen jurídico en el Derecho español y comparado, Cizur Menor, Thomson Reuters Aranzadi.

Gárate Castro, Francisco Javier (1984): El rendimiento en la prestación de trabajo, Madrid, Civitas.

Mella Méndez, Lourdes (1998): «Sobre una nueva manera de trabajar: el teletrabajo», Aranzadi Social, 5, 641-666.

Mella Méndez, Lourdes (2003): «Comentario general al Acuerdo Marco sobre el Teletrabajo», Relaciones Laborales, 1, 177.

Mella Méndez, Lourdes (2015): "La seguridad y salud en el teletrabajo», en Mella Méndez, Lourdes (dir.) y Villalba Sánchez, Alicia (coord.), Trabajo a distancia y teletrabajo. Estudios sobre su régimen jurídico en el Derecho español y comparado, Cizur Menor, Thomson Reuters Aranzadi.

Mella MÉndez, Lourdes (2016): «Nuevas tecnologías y nuevos retos para la conciliación y la salud de los trabajadores", Trabajo y derecho, 16, 30-52.

Morgado Panadero, Purificación (2004): «El teletrabajo: nueva forma de prestación de servicios», Actualidad Laboral, 16, 1911.

Pérez de los Cobos Orinuel, Francisco (2005): «La subordinación jurídica frente a la innovación tecnológica", Relaciones Laborales, 10, 1315.

Pérez de los Cobos Orinuel, Francisco y Thibault Aranda, Javier (2001): El teletrabajo en España. Perspectiva jurídico laboral, Madrid, Ministerio de Trabajo y Asuntos Sociales.

Purcalla Bonilla, Miguel Ángel y Preciado Domènech, Carlos Hugo (2013): «Trabajo a distancia vs. teletrabajo: estado de la cuestión a propósito de la reforma laboral de 2012", Actualidad Laboral, 2, 214.

Sempere Navarro, Antonio Vicente y Kahale Carrillo, Djamil Tony (2013): Teletrabajo, Madrid, Francis Lefebvre.

Sierra Benítez, Esperanza Macarena (2011): El contenido de la relación laboral en el teletrabajo, Sevilla, Consejo Económico y Social de Andalucía.

Thibault Aranda, Javier (2000): El teletrabajo, Madrid, Consejo Económico y Social.

Thibault Aranda, Javier (2006): «Teletrabajo forzado a domicilio», Actualidad Laboral, 4, 386. 